matter further, not simply on a fudge it/fix it kind of basis, but rather on precisely the principles which I have been setting out in this paper that is for the building up of the Church, for its edification and sanctification, given that there were clear and persisting strong divergent and differing views on the subject of the ordination of women even given the Synod vote-how is it possible for us to live in the highest possible degree of communion and what arrangements would be thus in the Church's best interests?

Now I could speak at much greater length and in considerably greater detail and I should not wish to be wanting to claim too much for such arrangements as we now do have in place which I entirely admit are themselves anomatous-but no more or less anomalous I would suggest than the actual provisions in the Measure which if they had been operated as envisaged would undoubtedly have led to 'no go' dioceses and done substantially greater damage to the Church of England in the immediate as well as in the longer term future.

The point I want to emphasize is that neither the London. Plan nor the Act of Sýnod set out detailed provisions. They offered a framework; some broad principles-that 'mean' between the two extremes of which the Preface to the Book of Common Prayer speaks, the 'regula' not the detailed rules to govern the family affairs of the Church-in which and with which the Church seeks to live through this disputed question mindful of the urgency of the mission entrusted to it by the Saviour to go into all the world and preach the Gospel: More importantly, given the world itself wounded; torn, divided and rent asunder in all manner of ways, the overwhelming question at all times in my mind was how was it possible for the Church quite properly preaching its message of reconciliation, renewal and hope, how was it possible given the division within its own ranks to reflect these very ingredients in the shaping and fashioning of its own continuing life?

I rather suspect I may have begun to go somewhat beyond my brief for this evening. Nevertheless, I hope that I have been able to set before you some more general thoughts and reflections, setting out as it were the backdrop to the more detailed and practical matters with which you will be further occupied during the course of this conference.

\title{
DAY CONFERENCE LONDON 1998
}

Where? Vaughan House, 46 Francis Street, SW1

When? Saturday, 28th March, 10.00 am to $4.00 \mathrm{pm}$

Topic? Anglican/Methodist Union Past and Future

Speakers?

To be announced

Book the date NOW Full details later 